\title{
Cervical cytochemistry: a potential adjunct to cytomorphology for detection of abnormal cells in cervical cancer screening
}

\author{
Indrani Krishnappa ${ }^{1}$, Kalyani R ${ }^{2}$, Raja Parthiban ${ }^{1}$, Abhishek Agrawal ${ }^{1}$ \\ ${ }^{1}$ Department of Pathology, MVJ Medical College \& Research Hospital, Bangalore, India \\ ${ }^{2}$ Department of Pathology, Sri devraj Urs Medical College, Kolar, India
}

Keywords:

CAP-Pap stain;

Cervical cancer;

Pap stain;

\section{ABSTRACT}

Background: Pap smear examination has been universally used as an effective screening tool for early detection of cervical carcinoma. The aim of this study was to assess the utility of Cervical Acid Phosphatase staining as an adjunct to routine Pap smear testing to improvethe sensitivity and specificity of routine Pap smear examination for cervical cancer detection.

Materials and Methods: Cervical smears were taken from patients attending the gynecology department and a few cervical cancer screening programmes. One set of slides were alcohol fixed and stained with rapid pap stain and another set of slides were fixed in a special fixative and stained with Cervical Acid Phosphatase -Pap stain. The nuclear features of these Cervical Acid Phosphatase stained dysplastic cells was studied on Pap stain to diagnose cervical intraepithelial lesion/ malignancy.

Results: Out of 489 cases included in the study 6 cases were diagnosed with intraepithelial lesion/ malignancy. On Cervical Acid Phosphatase -Pap stain 2 of the cases diagnosed as inflammatory smears on pap stain showed Cervical Acid Phosphatase positivity and thus were re evaluated. Mild nuclear atypia was observed in the Cervical Acid Phosphatase positive cells and these cases were diagnosed as Low grade squamous intraepithelial lesion and later biopsy proven to be Cervical intraepithelial Neoplasia I. Therefore Cervical Acid Phosphatase -Pap test was 100\% sensitive and specific for cervical cancer detection.

Conclusion: : With 100\% sensitivity Cervical Acid Phosphatase -Pap test satisfies the criteria of an efficient screening test.

\section{Correspondence:}

Dr. Indrani Krishnappa, $M D$

Associate Professor, Department of Pathology

MVJ Medical College \& Research Hospital

Email: indranipramodh@gmail.com

Reveived : Feburary $24^{\text {th }} 2020 ;$ Accepted : March $28^{\text {th }} 2020$

Citation: : Krishnappa I, Kalyani R, Parthiban R, Agrawal A. Cervical Cytochemistry: A Potential Adjunct to Cytomorphology for Detection of Abnormal Cells in Cervical Cancer Screening. J Pathol Nep 2020;10:1639-44 DOI: 10.3126/jpn.v10i1.27880

Copyright: This is an open-access article distributed under the terms of the Creative Commons Attribution 4.0 International License, which permits unrestricted use, distribution, and reproduction in any medium, provided the original author and source are credited.

\section{INTRODUCTION}

Cervical cancer is the second most common cancer in India accounting for $22.86 \%$ of all cancer cases in women. ${ }^{1}$ One woman dies of cervical cancer in India every 8 minutes. $^{2}$ Cervical cancer screening using papanicolaou stain has been successful in early detection and thus proper management of cervical cancer. ${ }^{3}$ According to a recent survey done by Karthigeyan et al rural women are higher risk of developing cervical cancer as against their urban counterparts. ${ }^{4}$ Therefore we conducted this study to screen the rural women of our area for cervical cancer using dual tests namely cytomorphology and cytochemistry. Taking into account the bulk of cases which need to be screened in these screening 
camps, cytochemistry reduces the risk of false negative reporting. Dual method of screening using cytomorphology as well as cytochemistry can improve our detection rates and thus aid in timely and appropriate management of cervical cancer cases if detected. Early detection and appropriate management can better the survival rates. The aim of this study is to perform and interpret Papanicolaou and cervical acid phosphatase (CAP) staining on conventional cervical smears, compare cytomorphology findings with enzyme cytochemistry findings and to correlate cytomorphology and enzyme cytochemistry findings with histological diagnosis wherever available.

\section{MATERIALS AND METHODS}

Inclusion criteria: All patients undergoing cervical smear examination at our OBG OPD between January 2018 and December 2018 where included in the study. Besides this we also conducted a few cervical cancer screening camps and females were subjected to cervical smear examination, these cases were also included in this study. Informed consent was obtained from every patient and this project was ethically cleared by the Institutional ethical clearance committee.

Exclusion criteria: Unsatisfactory smears with inadequate cellularity were excluded from the study. Cases previously diagnosed and treated (radiotherapy) for cervical cancers were also excluded.

Method of collection: Four smears (two ectocervical \& two endocervical) were taken simultaneously, one set was alcohol fixed and another was air dried.

Staining: Alcohol fixed smears were stained with rapid pap kit as per the manufacturer's instructions.

Air dried smears were first fixed with a fixative solution. This fixative solution was prepared by mixing $15 \mathrm{ml}$ citrate solution, $15 \mathrm{ml}$ distilled water, $60 \mathrm{ml}$ acetone \& $10 \mathrm{ml}$ $4 \%$ formalin. Air dried smears were fixed in this fixative for 1 minute and then stored at 2 centigrade in a dust free container.

CAP staining procedure: $0.5 \mathrm{ml}$ of Fast Garnet GBC Base solution and $0.5 \mathrm{ml}$ of Sodium nitrite solution were mixed gently and let to stand for 2 mins

The above solution ( $1 \mathrm{ml}$ ) was mixed with $45 \mathrm{ml}$ deionised prewarmed water, $0.5 \mathrm{ml}$ Naphthol AS-BI phosphate solution and $2 \mathrm{ml}$ acetate solution.

Pre fixed slides were incubated in the solution prepared in step 2 for 1 hour in 37 degree water bath.

After incubation slides were rinsed thoroughly in deionised water and counter stained with hematoxyllin solution.

\section{Evaluation of CAP - PAP smears:}

Acid phosphatase activity appears as purplish to dark red granules in the cytoplasm of endocervical cells, squamous metaplastic cells, inflammatory cells like leucocytes \& histiocytes and thus these cells were taken as internal control. Cytomorphology of the other cells showing acid phosphatase staining (other than these positive controls) was studied in detail to distinguish abnormal cells.

\section{RESULTS}

The current study included cervical smears taken from 489 patients attending the OBG OPD and various cervical cancer screening camps. The mean age of the subjects was 35 years (range 25-55 years). Cytomorphological features on routine pap \& CAP-Pap staining is shown in table 1 .

Out of the 489 cases 483 were reported as negative for intraepithelial lesion/ malignancy. These included normal smear (142), inflammatory smears (204), atrophic smears (56), candidiasis (30), trichomonas vaginalis (8) and bacterial vaginosis(43). Of the remaining smears we had 2 cases of squamous cell carcinoma, 2 cases of atypical

Table 1: Histopathological Diagnosis of all pigmented lesions

\begin{tabular}{|c|c|c|c|}
\hline Lesions & Pap (489 cases) & & \\
\hline Normal Smear & 142 & Positive & Negative \\
\hline Atrophic Smear & 56 & - & 56 \\
\hline Candidiasis & 30 & - & 30 \\
\hline Trichomonas Vaginalis & 08 & - & 08 \\
\hline Bacterial vaginosis & 43 & - & 42 \\
\hline Inflammatory smear & 204 & 2 & 202 \\
\hline ASCUS & 2 & 1 & 1 \\
\hline LSIL & 1 & 1 & - \\
\hline HSIL & 1 & 1 & - \\
\hline SCC & 2 & 2 & - \\
\hline Total & 489 (6 positive) & 7 & 482 \\
\hline
\end{tabular}


Table 2: Comparison of pap, CAP-PAP \& cervical biopsy in all CAP-PAP positive cases $(\mathrm{n}=8)$

\begin{tabular}{|c|c|c|c|c|c|c|}
\hline \multirow[t]{2}{*}{ Pap smear } & \multirow[t]{2}{*}{ CAP positive } & \multicolumn{5}{|c|}{ Cervical biopsy (N=8) } \\
\hline & & NILM & CIN I (Fig 1) & CIN II (Fig 2) & CIN III & SCC (Fig 3) \\
\hline Inflammatory smear (2) & LSIL (2) & - & 2 & - & - & - \\
\hline ASCUS (2) & NILM (1), LSIL (1) & 1 & 1 & - & - & - \\
\hline LSIL (1) & LSIL (1) & - & - & 1 & - & - \\
\hline HSIL (1) & HSIL (1) & - & - & - & - & 1 \\
\hline $\operatorname{SCC}(2)$ & $\operatorname{SCC}(2)$ & - & - & - & - & 2 \\
\hline Total (8) & & 1 & 3 & 1 & $\mathbf{0}$ & 3 \\
\hline
\end{tabular}

squamous cells of undetermined significance ASCUS, one case each of low grade intraepithelial lesion (LSIL) and high grade squamous intraepithelial lesion (HSIL).

On re-evaluation with CAP - pap stain one of the cases of ASCUS and two cases which was reported as inflammatory smears were diagnosed as LSIL. In these cases strong acid phosphatase positivity was seen in the epithelial cells, and on detailed observation few of the cells showed mild nucleomegaly and nuclear membrane irregularity, thus these cases were finally evaluated as LSIL.

\section{Histopathology results}

Cervical biopsy was done in six cases and hysterectomy was done in the two cases of squamous cell carcinoma. Out of the six biopsy cases, there were 3 cases of CIN II, 2 cases of CIN I and one case of squamous cell carcinoma (diagnosed as HSIL on pap smear/ CAP-pap test). Both the hysterectomies showed cervical squamous cell carcinoma.

\section{Comparison between CAP-PAP and histopathology results}

Comparison between CAP-Pap and histopathology findings is shown in table 2. Among the 7 cases of reported intraepithelial lesion/ malignancy on CAP-PAP test [Squamous cell carcinoma (2 cases), high grade squamous intraepithelial lesion (1 case)\& low grade squamous intraepithelial lesion (4 cases)], biopsy was available in all the cases. Cytohistopathological correlation was seen in 5 cases ( 2 cases of SCC \& 3 cases of LSIL). The case reported as HSIL on pap smear turned out to be invasive SCC and another case diagnosed as LSIL showed features of lower two third involvement by dysplasia on cervical biopsy and thus was reported as CIN II finally.

In comparion with cervical biopsy, pap smear testing was found to be $100 \%$ specific and $75 \%$ sensitive. Taking into account CAP-pap testing and cervical biopsy, this dual testing modality of enzyme cytochemistry and morphological testing was found to be $100 \%$ specific and sensitive in our study. Besides being cheap, quick and easy to perform, CAP-Pap test shows $100 \%$ sensitivity, thus qualifying to be a good screening test for early detection of cervical intraepithelial lesions and malignancies.

\section{DISCUSSION}

Cervical smear cytology has been widely used as a screening tool for cervical cancers; however it has significant rates of false positive \& false negative results. 5,6Various techniques have been developed to improve the cervical cancer detection rates like thin prep cervical cytology, use of magnified chemiluminescent screening examination (speculoscopy) with pap smear (Papsure), detection of HPV DNA by hybrid capture (HC 2) or polymerase chain reaction tests, telomeric repeat amplification protocol (TRAP), Fourier-transform infrared spectroscopy (FTIR) and immunocytochemical detection of p16INK4a protein. ${ }^{7}$ The major drawback of these advanced tests is the cost factor and since the incidence of cervical cancer is higher in the rural areas, these newer techniques have a limited role in mass screening programmes in developing countries like ours.

Histochemical reactions demonstrating enzymes like ribnucleic acid, glycogen, acid phosphatase, non specific esterase, glucoronidase and phosphamidase have been used in the past to distinguish benign from malignant lesions of uterine cervix, endometrium, buccal mucosa and also mesothelial lining like pleura and peritoneum..$^{8-13}$ Amongst these acid phosphatase is an easily demonstrable intracellular enzyme and thus has been studied by many authors for detection of cervical malignancies.

CAP-Pap technique of Markovic is a simple, effective, single slide double staining method for early detection of cervical cancer. ${ }^{5,14}$ Normal cervical epithelium contains acid phosphatase and the enzyme activity reduces from basal to intermediate and superficial cells, thus rendering the superficial and intermediate cells negative for acid phosphatase staining. However in case of dysplasia acid phosphatase staining is always positive. Therefore cervical acid phosphatase acts a natural biomarker to distinguish normal from abnormal cervical epithelial cells. ${ }^{15}$ Thus Cappap stain improves visibility of abnormal cells so that these can be evaluated for nuclear abnormalities subsequently. 


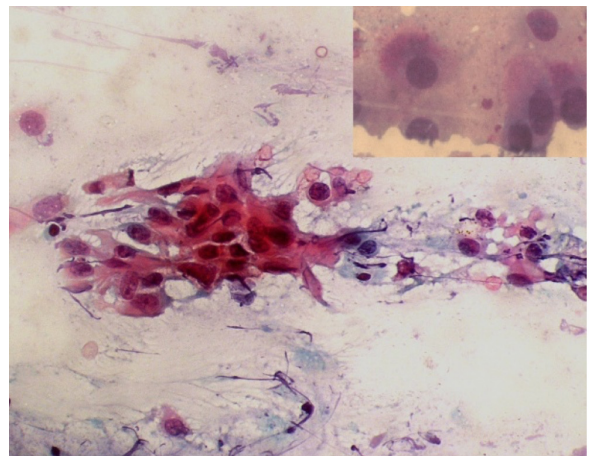

Figure 1: A. Cervical smear showing intermediate cells with mild nuclear atypia, irregular nuclear membrane and prominent nucleoli-LSIL, Pap stain 40X, (Inset, CAPPap stain).

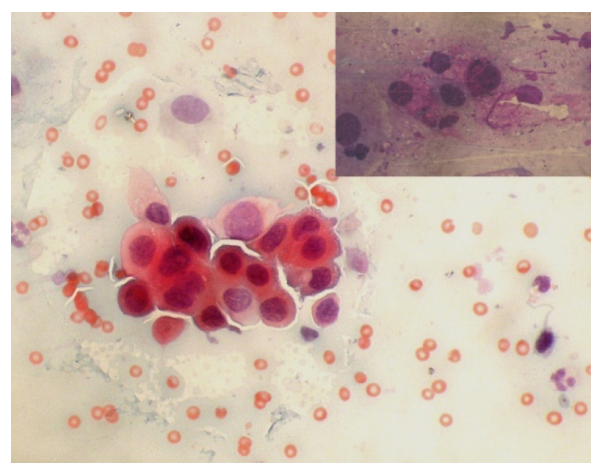

Figure 2: A. Cervical smear showing small sized cells with dysplastic features - HSIL, Pap stain 40X (Inset, CAP-Pap stain).

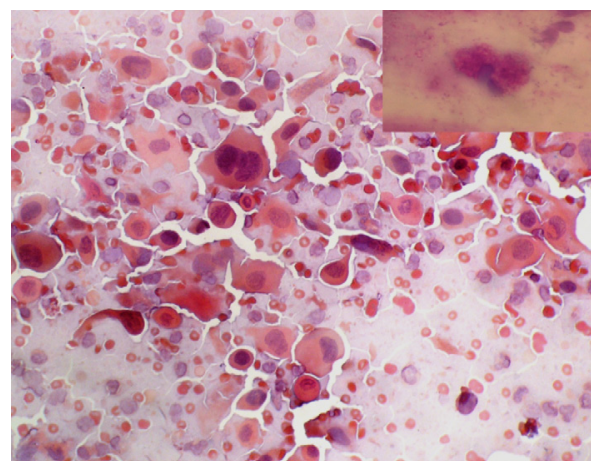

Figure 3: A. Cervical smear showing highly dysplastic cells and background tumour diathesis - SCC, Pap stain 40X (Inset, CAPPap stain).

Acid phosphatase granules are present in the normal endocervical, squamous metaplastic and inflammatory cells which can be taken as in built positive controls. ${ }^{16}$

Our study was designed to compare the efficacy of CAPPAP test with conventional pap test for screening cervical cancers. CAP-PAP test showed 100\% sensitivity and specificity for detecting abnormal cervical epithelial cells in our study. Similar observations were seen in various other studies done by Deb et al, Niranjan J et al \& Batra N

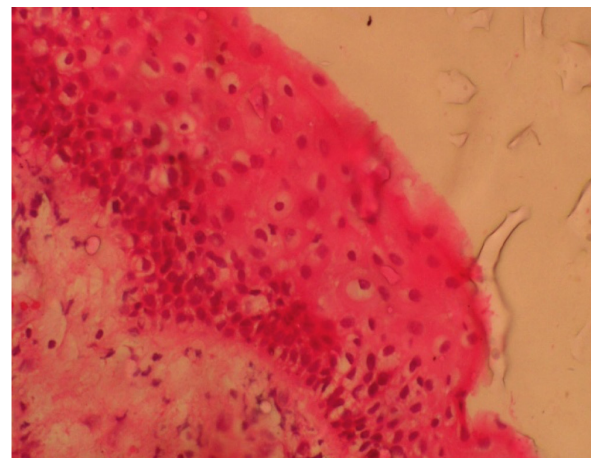

Figure 1: B. Cervical epithelium showing lower 1/3rd dysplasia and koilocytic change, CIN I (HE stain, X40)

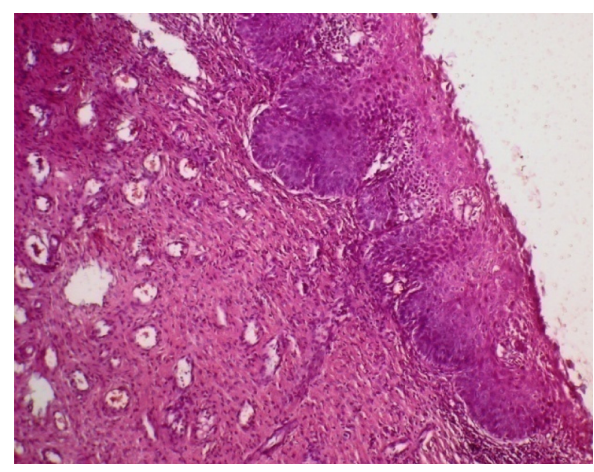

Figure 2: B. Cervical epithelium displaying lower 2/3rd dysplasia-CIN II (HE stain, X40)

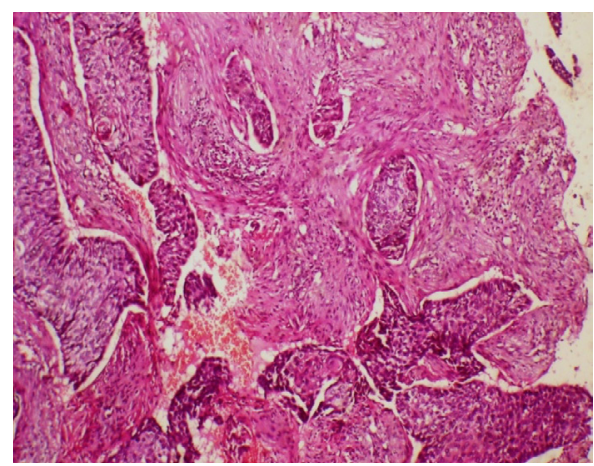

Figure 3: B. Histopathology section of moderately differentiated squamous cell carcinoma cervix (HE stain, X40)

et al. 7,16,17 The most important aspect of present study was that acid phosphatase positivity prompted re evaluation of cervical smears in two cases which were reported as inflammatory smears on conventional smears. Eventually these cases were biopsy proven to be cervical intraepithelial neoplasia II (CIN II). One of the cases reported as atypical squamous cells of undetermined significance (ASCUS) which showed few positive acid phosphatase granules in the cytoplasm was upgraded to LSIL and biopsy proven as CIN I. Markovic et al in their initial study also documented 
similar findings of improved detection rates of abnormal cells on CAP-Pap and thus decreased false negatives on cervical smear testing. ${ }^{15}$

Although CAP-pap test shows $100 \%$ sensitivity and specificity it has its own limitations. In few instances the cytoplasmic granules were overstained and obscured the nuclear details. Nuclear details being the major criteria for differentiating squamous intraepithelial lesions/ malignancies from normal cells, overstained cytoplasmic granules posed a major problem in interpreting these slides. This is a major hindrance in cases of high grade intraepithelial lesion (HSIL) as the size of cells is smaller and nuclear details are obscured by the cytoplasmic granucles. However many authors did not encounter this issue. ${ }^{15,17-19}$ Besides this acid phosphatase staining is normally seen in the endocervical and metaplastic cells and occasionally these cells show mild nuclear enlargement which can be misinterpreted as dysplasia. In such cases a conventional pap smear is essential for proper evaluation of nuclear features. Deb et al have suggested a two tier screening procedure by a cytotechnologist and an experienced cytopathologist to overcome this issue of false positive reporting in Cap-pap smears. $^{7}$

Another major drawback of CAP-pap testing is that it cannot be used efficiently for diagnosis of glandular lesions like endocervical adenocarcinoma and adenocarcinoma in situ, as all the endocervical cells show positive staining and are taken as positive control in these slides. In our study however we did not encounter any glandular lesions and therefore did not encounter this problem.

Few of the limitations of our study were the low sample size and limited variety of lesions. With a larger sample size we could have deduced more accurate results pertaining to the utility of CAP-Pap test. Since we did not have any glandular lesions in our study we could not assess the use CAP-Pap testing in diagnosis of endocervical lesions.

\section{CONCLUSIONS}

CAP-Pap test is an efficient screening tool for cervical cancer as it is highly sensitive and thus satisfies the criteria for a good screening test. The rate of false negatives can be significantly reduced with this dual test of assessing the cytochemistry along with cytomorphology. In our study we found that CAP-pap test is of great use in selecting smears for re screening. Once CAP positive cells are detected on cervical smears we tend to keenly observe those cells selectively for nuclear abnormality and invariably in our study the cases which were re evaluated based on cytochemistry turned out to be positive for dysplasia. Therefore CAP-pap test can be effectively used in cervical cancer screening programmes where large number of smears needs to be screened by the cytopathologist. This reduces the burden on the cytopathologist as only CAP positive smears can be evaluated in detail for diagnosis of cervical dysplasia. Further this test can also be used in low resource settings lacking trained cytologists. When used along with conventional pap staining, acid phosphatase can improve the sensitivity of the former and thus increase the rate of cervical cancer detection in mass screening programmes.

\section{Acknowledgement:}

We profoundly thank the "Advanced medical research wing, Rajiv Gandhi University of health sciences (RGUHS)" for financial support.

\section{Conflict of interest: None}

\section{REFERENCES}

1. Guidelines for Cervical Cancer Screening Programme. Government of India-World Health Organization Collaborative Programme (2004-2005). Website

2. WHO Summary report on HPV \& cervical cancer statistics in India $(18 / 03 / 2008)$

3. Human Papillomavirus and Related Diseases Report. WHO/ICO Information Centre on HPV and Cervical Cancer (HPV Information Centre).Human Papillomavirus and Related Cancers in India. Summary Report 2019;(iv). Website

4. Karthigeyan K.Cervical cancer in India and HPV vaccination.Indian J Med Paediatr Oncol 2012;33:7-12. Crossref

5. Markovic O, Markovic N.Can acid phosphatase reduce pap test fasle negative readings?J Natl Cancer Inst 1997;89:1459. Crossref

6. Volgareva G, Zavalishina L, Andreeva Y, Frank G, Krutikova E, Golovina D et al. Protein p16 as a marker of dysplastic and neoplastuc alterations in cervical epithelial cells.BMC Cancer 2004;4:58. Crossref

7. Deb P, Iyer V K, Bhatla N, Markovic O, Verma K. Cervical Acid Phosphatase detection: A guide to abnormal cell in cytology smear screening for cervical cancer. Journal of Cytol 2008;25:1-5. Crossref

8. Gross S J, Kinzie G. Cytochemistry of bening and malignant squamous epithelium of the cervix uteri. Aid phosphates, non specific esterase and alkaline phosphatase. Obstet Gynecol 1960;15:261-79. Website

9. Danziger S, Gross SJ. Histochemical techniques applied to the study of benign and malignant squamous epithelium of the cervix uteri. Am J Obstet Gynecol 1957;73:94-119. Crossref

10. Walker BS, Lemon HM, Davison MM, Schwartz MK. Acid phosphatases; a review. Am J Clin Pathol 1954;24:807-37. Crossref

11. Blonk DI, Schaberg A, Willighagen RG. Enzyme cytochemistry of benign and malignant cells in pleural and peritoneal fluid. Acta Cytol 1967;11:460-5. Website

12. Fishman WH, Mitchell GW Jr, Dimitrakis H, Hayashi M. Enzymorphology of adenocarcinoma of the endometrium; betaglucuronidase, acid phosphatase, reduced diphosphopyridine nucleotide (DPNH) diaphorase, and alpha-naphthyl esterase. Cancer 1963;16:126-32. Crossref

13. Santis H, Shklar G, Chauncey HH. Histochemistry of experimentally induced leukoplakia and carcinoma of the hamster buccal pouch. Oral Surg Oral Med Oral Pathol 1964;17:207-18. Crossref

14. Scambia G, Benedetti P, Ferradina G et al. Cathepsin D assay in ovarian cancer; correlation with pathologic features and receptors for estrogen, progesterone and epidermal growth factor. Brit J Cancer 1991;64:182. Crossref

15. Markovic O, Markovic N, Belledone M. Cervical acid phosphatase - Papanicolaou (CAP-PAP) test. J Histotechnology 1999;22:43-7. 
Crossref

16. Niranjan J, C. J. Prakash. Cervical Acid Phosphatase: Evaluation as an Adjuvant to Papanicolaou Smear Screening in Cervical Cancer Detection. Journal of Evidence based Medicine and Healthcare 2015;2:714-23. Crossref

17. Batra N, Agarwal, Santwani PM. Study of cap pap versus conventional pap in suspicious cervical lesions. Int J Res Med 2015;4:102-8. Website

18. Markovic O, Markovic N. Cervical acid phosphatase: a biomarker of cervical dysplasia and a potential surrogate endpoint for colposcopy. Dis Markers 2004;19:279-86. Crossref
19. Markovic O, Markovic N, Belledone M. Cervical acid phosphatase - Papanicolaou (CAP-PAP) test. J Histotechnology 1999;22:43-7. Crossref

20. Markovic O, Markovic N. Acid phosphatase in cervical smears (CAPPAP test). Arch Oncol 1998;6:137-9. Crossref 